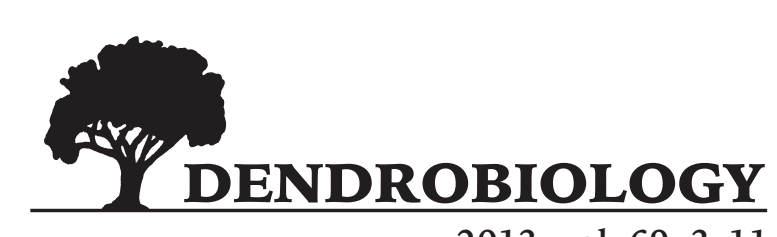

2013, vol. 69, 3-11

\author{
Lin Lin, Qichao Yao, Huanwen Xu, Huaizhi Mu, Jing Jiang*
}

\title{
Characteristics of the staminate flower and pollen from autotetraploid Betula platyphylla
}

Received: 5 April 2012; Accepted 10 June 2012

\begin{abstract}
Comparison of the staminate flower and pollen of Betula platyphylla between autotetraploid and diploid individuals may reveal the reason for cross sterility when an autotetraploid male parent is crossed with a diploid female parent. Staminate flowers and pollen from seven autotetraploid individual trees were examined. The morphologies of the staminate flower and pollen and pollen germination of these autotetraploid individuals were compared with diploid trees. The structure of the staminate flower did not differ between autotetraploids and diploids, whereas the size of the staminate flower was larger in the autotetraploids compared with the diploids. The mean diameter and pore depth of the pollen were significantly larger in autotetraploid individuals compared with diploids, and several abnormalities in pollen morphology were found commonly amongst pollen from the autotetraploid trees. The germination rate of pollen from autotetraploids was significantly inferior to that of diploids and there was a significant negative correlation between germination rate and the percentage of abnormal pollen. These results demonstrate that the autotetraploid should not be chosen as the male parent to obtain hybrid triploid progenies because the pollen is abnormal and results in low fertility despite its large size. The results provide important information for selecting and distributing parent strains with the aim of building seed orchards of triploid birch trees.
\end{abstract}

Additional key words: birch, germination rate, pollen morphology, polyploidy

Address: L. Lin, Q. C. Yao, H. W. Xu, H. Z. Mu, J. Jiang*: State Key Laboratory of Forest Genetics and Tree Breeding, Northeast Forestry University, 150040, Harbin, China, e-mail: jiangjing1960@yahoo.com.cn *corresponding author

\section{Introduction}

The natural European aspen (Populus tremula) triploid was discovered in Sweden by Nilsson-Ehle (1936) and Müntzing (1936). Since then, plant-breeding scientists have given extensive attention to creating triploids in forest tree species due to the huge growth of forestry. One possible approach to breed triploids is to undertake artificial pollination using unreduced $2 n$ pollen that exists in natural pollen populations to pistillate flowers of diploids. Nevertheless, this is not a simple because unreduced $2 n$ pollen is scarce in nature and is unable to complete germination with the typical $n$ pollen, meaning that such ordinary pollination often results in just a small quantity of triploids. After Blakeslee and Avery (1937) discovered that colchicine can loosen the spindle fibers during cell division and induce chromosome doubling, a new method for plant breeding was developed, and this is known as triploid breeding. Since then, this technology has been used extensively in many fields of forestry breeding, especially for Populus spp. Johnsson and Eklundh (1940) obtained triploids using artificial pollination with $2 n$ pollen (induced by colchicine treatment) to pistillate flowers of diploid strains of $P$. tremula and P. tremuloides. Since this first report, artifi- 
cial pollination with $2 n$ pollen to pistillate diploid flowers has been used to produce triploids in $P$. canescens, $P$. balsamifera, $P$. tremula, $P$. tremuloides and $P$. tomentosa (Einspahr 1984; Zhu et al. 1997; Kang 2003).

Members of the genus Betula form a particularly significant group of broadleaved trees that grow naturally in Eurasia and North America. Certain birch species, such as B. platyphylla, B. pendula, B. pubescens and $B$. papyrifera, are valuable sources of wood, and breeding work aimed at their economic improvement is of great importance (Valanne 1972; Eriksson and Jonsson 1986). The natural triploid of the European birch (Betula verrucosa) was discovered by Löve (1944). This triploid shows "gigantism" with respect to the morphology of its breast-height diameter, leaf and fruit. Furthermore, Johnsson (1956) used two different tetraploids (B. verrucosa and Betula japonica $\times$ B. verrucosa) as female parents with a diploid ( $B$. verrucosa) as the male parent to obtain triploid progenies from open pollination. In theory, a certain quantity of $2 n$ pollen exists in the pollen population produced by autotetraploids. Consequently, triploids could be obtained through hybridization of an autotetraploid male parent with a diploid female parent. However, there have been no reports of triploids obtained through this approach in Betula. Previous research has reported that there is morphological variation in the pollen produced by Betula spp. Nevertheless, there are no reports concerning the staminate flower or the relationship between germination and the morphology of pollen produced by autotetraploids. In 2004, 234 autotetraploids (B. platyphylla) were obtained after colchicine treatment. Attempts were made to obtain a triploid through hybridization between the autotetraploids and diploid lines in 2009. The progeny saplings were all triploid when the autotetraploid was the female parent and a diploid was the male parent $(+4 x \times \delta 2 x)$, whereas the seeds generated from crosses using a diploid as the female parent and the autotetraploid as the male parent ( $+2 x$ $\times \delta 4 x$ ) were all sterile (Mu et al. 2012). In order to reveal the reason for the cross sterility of $q 2 x \times \delta 4 x$, the staminate flowers and pollen from seven autotetraploid individuals were examined, and the morphology of these structures and pollen germination rates were compared between autotetraploid and diploid trees. The results provide important information for selecting and distributing parent strains with the aim of building seed orchards of triploid birch trees.

\section{Methods}

\section{Plant materials}

Mature staminate flowers and pollen samples were collected in April 2010 from seven autotetraploid individual trees (B. platyphylla, named Q12, Q13, Q14,
Q19, Q33, Q34 and Q103). Staminate flowers and pollen samples from 30 diploid individuals served as controls. The trees were located in an intensive seed orchard in Harbin, China.

\section{Staminate flower morphology measurements}

The lengths of mature male catkins were measured using a pair of vernier calipers. At least 30 healthy, undamaged and fully expanded catkins from each individual tree were measured, and these were selected at random. The structure of the cymule was examined and the length of the primary bract from the cymule was measured with a stereomicroscope (SteREO Lumar. V12, ZEISS, Germany). Cymules were chosen at the top, middle and bottom of each catkin, and 90 cymules and primary bracts were examined in total.

\section{Pollen morphology measurements}

Pollen samples were prepared and mounted in silicon oil as described by Karlsdóttir et al. $(2007 ; 2008)$. This method includes sequential treatment at $40^{\circ} \mathrm{C}$ in the following solutions: $10 \%(w / v) \mathrm{NaOH}$ for $15 \mathrm{~min}$, $10 \%(v / v) \mathrm{HCl}$ for $10 \mathrm{~min}, 40 \%(v / v) \mathrm{HF}$ for $5 \mathrm{~min}$ and $10 \% \mathrm{HCl}$ for $10 \mathrm{~min}$. Then the samples underwent acetolysis and dehydration in ethanol and TBA buffer. At least 1000 pollen grains from each individual tree were photographed and measured using a microscope (Axio Imanger A1, ZEISS, Germany). According to the method of Perveen and Qaisek (1999), only triporate pollen grains (normal grains with three pores) lying in polar view were used, and pollen diameter and pore depth were determined for each pollen grain. The pollen diameter was defined as the distance from the outside tip of the pore to the outer margin of the facing wall, whereas pore depth was defined as the distance from the outside tip of the pore to the inner margin of the nexine through the vestibulum. When the pollen shape was asymmetric, the largest diameter and pore depth measurements were used. Moreover, from the same preparations any abnormal pollen grains were examined and noted. At least 30 fields of pollen grains per individual tree were counted and all types of abnormalities were recorded.

\section{Pollen germination measurements}

Pollen germination was performed in vitro in agar culture medium. Briefly, molten culture medium (all $w / v: 0.015 \% \mathrm{H}_{3} \mathrm{BO}_{3}, 0.015 \% \mathrm{CaCl}_{2}, 0.5 \%$ agar, $20 \%$ sucrose; $\mathrm{pH}$ 6.0) was spread evenly on to microscope slides. Once solidified, pollen samples were blown evenly on to the culture medium surface using an aurilave until the color of the culture medium was slightly yellow. The slides covered in pollen grains were put into petri dishes between layers of moist filter paper and incubated at $25^{\circ} \mathrm{C}$ for $24 \mathrm{~h}$. After that, at least 30 fields of pollen grains per individual tree were 
examined using the microscope and the rate of germination was determined. A germinating pollen grain was defined to have a pollen tube of a length greater than the diameter of the grain itself.

\section{Statistical analysis}

All data were analyzed by analysis of variance (ANOVA), the Duncan test and Pearson's correlation coefficient. These tests were performed using the SPSS v16.0 software (SPSS Inc.).

\section{Results}

\section{Morphological variations of the staminate flower versus tree ploidy}

The structure of the staminate flower from autotetraploid trees did not differ from those from diploid trees; both were catkins comprised of several cymules arranged helically along an inflorescence axis. Each cymule consisted of one primary bract, two secondary bracts and three flowers. Furthermore, each flower consisted of two tepals and two stamens, and each stamen consisted of one filament and two anthers. Nevertheless, the staminate flower from autotetraploids was larger than measured for diploids (Fig. 1). The length of the catkin and primary bracts were significantly greater in autotetraploid individuals compared with diploids (Table 1). Mean catkin length for each autotetraploid individual was significantly greater than the lengths observed in the diploids, except for Q12 and Q33. The largest catkin (mean length of $107.80 \mathrm{~mm}$ ) was from Q19, and this was $30.22 \%$ greater in length than the mean catkin length observed for the diploids. The primary bract length of each autotetraploid individual was significantly greater than each of the diploids, except for Q13 and Q34. The largest primary bract (mean length of 3.21 $\mathrm{mm}$ ) was observed for Q14, and this was $20.68 \%$ greater than the primary bract lengths of the diploids (Table 2). However, there was no correlation between catkin length and primary bract length $(r=-0.415 ; P$ $=0.335 ; \mathrm{n}=7$ ) in different autotetraploid individuals. These results suggest that autotetraploids showed "gigantism" with respect to their staminate flower organs versus those observed in the diploid individuals.

\section{Germination and morphological variation of pollen versus ploidy}

Pollen germination rates differed significantly between the autotetraploids and diploids (Table 1). The pollen germination rate of each autotetraploid individual was significantly lower than each diploid individual (Fig. 2 and Table 2). The mean pollen germination rate of the seven autotetraploid individuals was only $12.51 \%$, which was $65.48 \%$ lower than the rate observed for the diploids. The maximal pollen germi-

Table 1. ANOVA of different traits from individual trees: catkin length, primary bract length, pollen diameter, pore depth, abnormal pollen percentage and pollen germination rate.

\begin{tabular}{lrrrrc}
\hline \multicolumn{1}{c}{ Dependent variable } & \multicolumn{1}{c}{$S S$} & $d f$ & \multicolumn{1}{c}{ MS } & \multicolumn{1}{c}{$P$} \\
\hline Catkin length & 18776.401 & 7 & 2682.343 & 22.422 & 0.000 \\
Primary bract length & 36.286 & 7 & 5.184 & 119.783 & 0.000 \\
Pollen diameter & 49100.163 & 7 & 7014.309 & 940.440 & 0.000 \\
Pore depth & 903.983 & 7 & 129.140 & 848.714 & 0.000 \\
Abnormal pollen percentage & 14.802 & 7 & 2.115 & 172.728 & 0.000 \\
Pollen germination rate & 2.358 & 7 & 0.337 & 191.088 & 0.000 \\
\hline
\end{tabular}

Table 2. Multiple comparisons of different individual trees with respect to catkin length, primary bract length, pollen diameter, pore depth, abnormal pollen percentage and pollen germination rate.

\begin{tabular}{|c|c|c|c|c|c|c|}
\hline Individual trees & Catkin length/mm & $\begin{array}{l}\text { Primary bract } \\
\text { length } / \mathrm{mm}\end{array}$ & $\begin{array}{c}\text { Pollen } \\
\text { diameter } / \mu \mathrm{m}\end{array}$ & Pore depth/ $/ \mu \mathrm{m}$ & $\begin{array}{l}\text { Abnormal pollen } \\
\text { percentage } / \%\end{array}$ & $\begin{array}{l}\text { Pollen germination } \\
\text { rate } / \%\end{array}$ \\
\hline Q12 & $88.39 \pm 5.89 c$ & $2.88 \pm 0.20 c$ & $26.78 \pm 3.11 \mathrm{~g}$ & $2.94 \pm 0.36 \mathrm{~g}$ & $69.20 \pm 12.37 b$ & $9.69 \pm 1.83 \mathrm{~d}$ \\
\hline Q13 & $104.83 \pm 12.45 \mathrm{a}$ & $2.65 \pm 0.18 \mathrm{~d}$ & $30.21 \pm 2.97 c$ & $3.67 \pm 0.47 \mathrm{a}$ & $58.29 \pm 13.28 c$ & $12.23 \pm 0.84 c$ \\
\hline Q14 & $95.06 \pm 6.26 \mathrm{~b}$ & $3.21 \pm 0.19 a$ & $27.35 \pm 3.26 f$ & $3.21 \pm 0.41 \mathrm{f}$ & $56.19 \pm 11.13 c$ & $13.47 \pm 1.74 \mathrm{bc}$ \\
\hline Q19 & $107.80 \pm 13.61 \mathrm{a}$ & $3.04 \pm 0.20 b$ & $28.21 \pm 2.68 \mathrm{e}$ & $3.31 \pm 0.41 \mathrm{e}$ & $43.51 \pm 10.88 \mathrm{~d}$ & $14.90 \pm 3.64 b$ \\
\hline Q33 & $83.05 \pm 7.03 c$ & $3.17 \pm 0.18 \mathrm{a}$ & $29.27 \pm 2.68 \mathrm{~d}$ & $3.48 \pm 0.40 c$ & $46.18 \pm 11.01 d$ & $13.75 \pm 2.22 b c$ \\
\hline Q34 & $99.21 \pm 12.29 b$ & $2.58 \pm 0.11 \mathrm{e}$ & $31.59 \pm 2.11 \mathrm{a}$ & $3.35 \pm 0.33 \mathrm{~d}$ & $44.41 \pm 8.01 \mathrm{~d}$ & $14.39 \pm 2.01 b$ \\
\hline Q103 & $98.45 \pm 13.96 b$ & $2.93 \pm 0.31 c$ & $30.63 \pm 2.99 b$ & $3.56 \pm 0.41 b$ & $77.36 \pm 9.28 \mathrm{a}$ & $9.16 \pm 2.13 \mathrm{~d}$ \\
\hline Control & $82.78 \pm 12.15 c$ & $2.66 \pm 0.24 \mathrm{~d}$ & $23.32 \pm 1.68 \mathrm{~h}$ & $2.58 \pm 0.31 \mathrm{~h}$ & $4.02 \pm 1.28 \mathrm{e}$ & $36.24 \pm 8.01 \mathrm{a}$ \\
\hline
\end{tabular}

Columns containing different lower-case letters differ significantly $(P<0.05)$. 
a
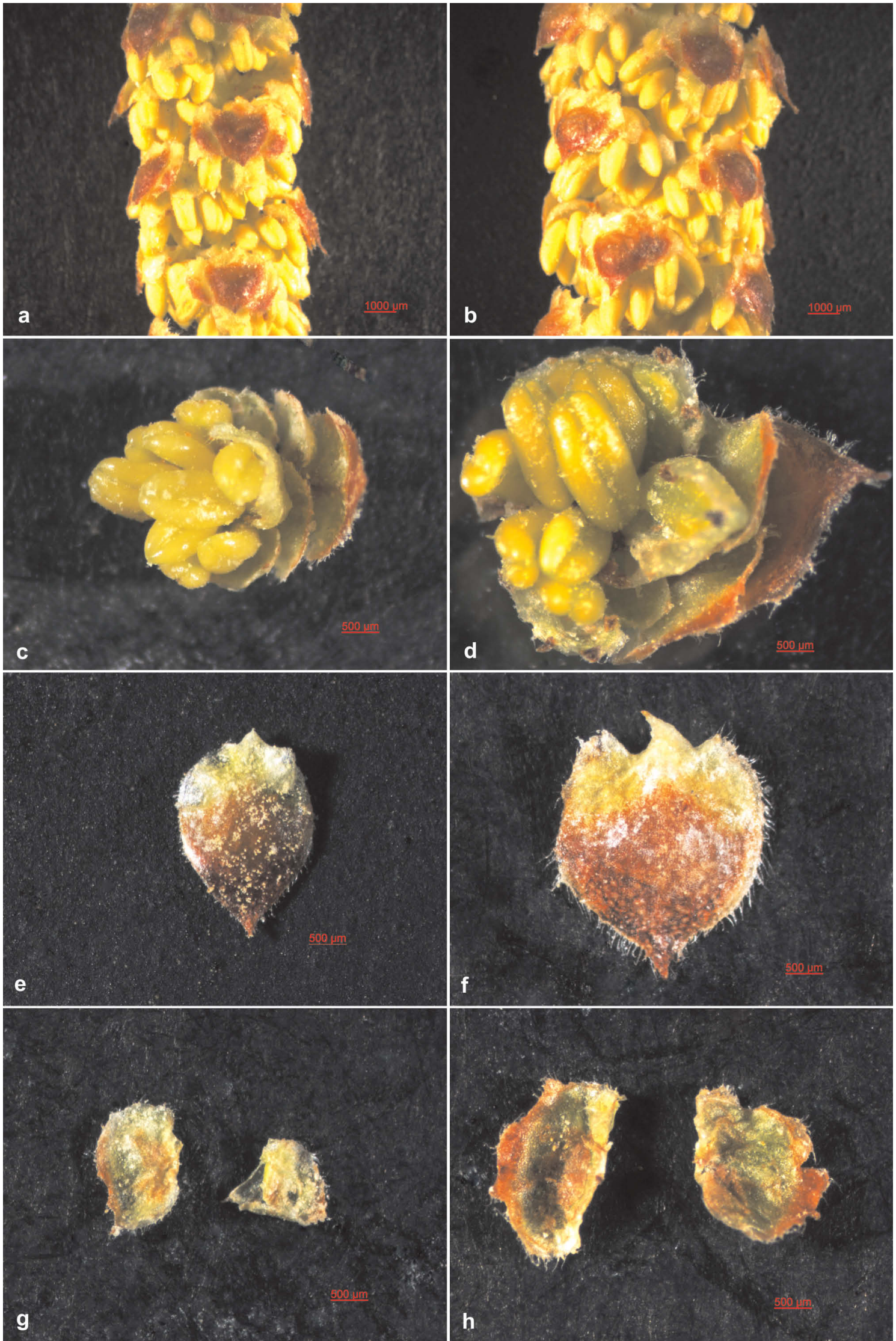

Fig. 1. Staminate flowers from diploid and autotetraploid individuals

a - part of a mature catkin from the diploid, b - part of a mature catkin from the autotetraploid, $c$ - cymule of the diploid, $d$ - cymule of the autotetraploid, $\mathrm{e}$ - primary bract of the diploid, $\mathrm{f}$ - primary bract of the autotetraploid, $\mathrm{g}$ - secondary bracts of the diploid, $\mathrm{h}$ - secondary bracts of the autotetraploid

b
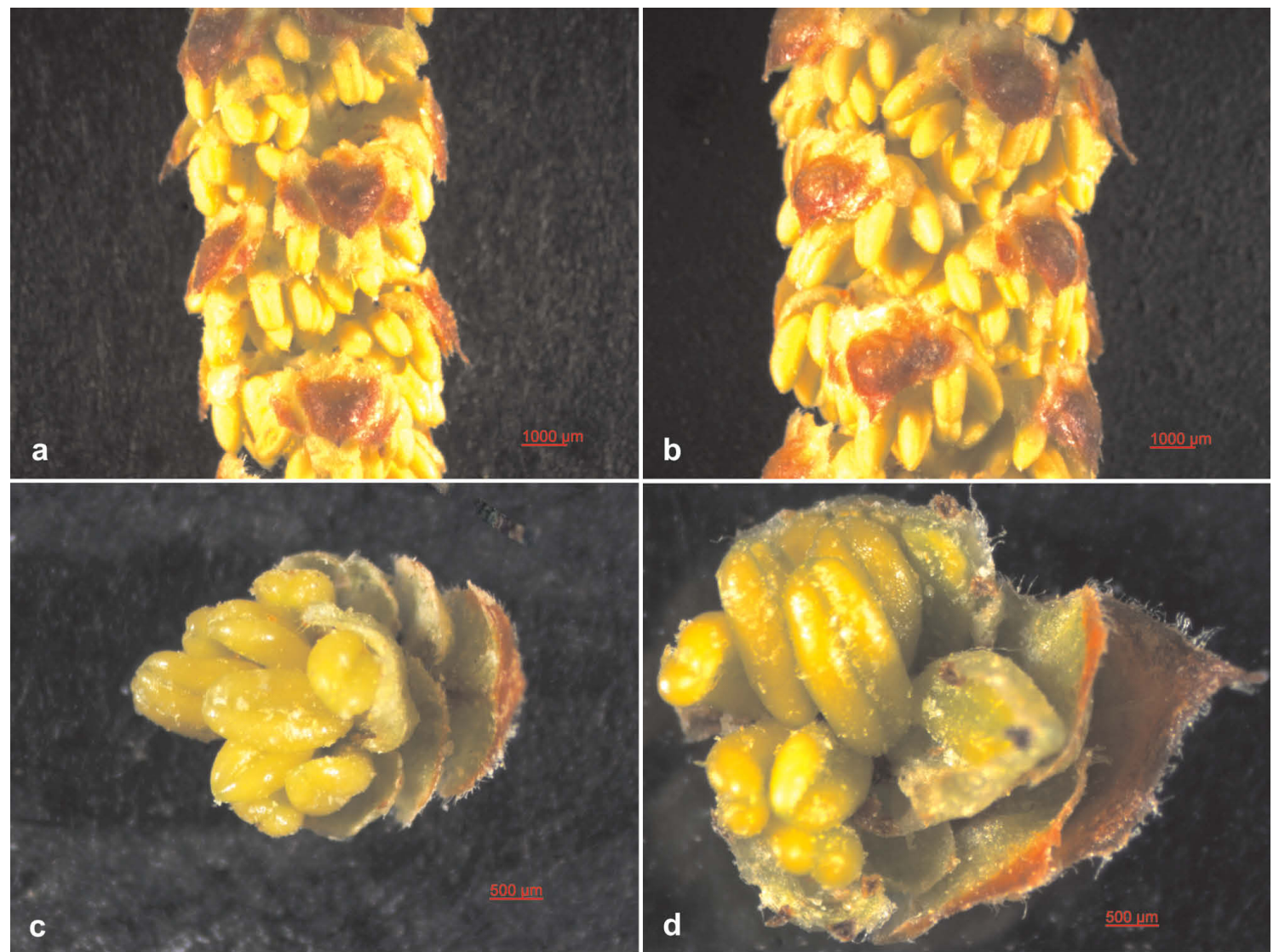


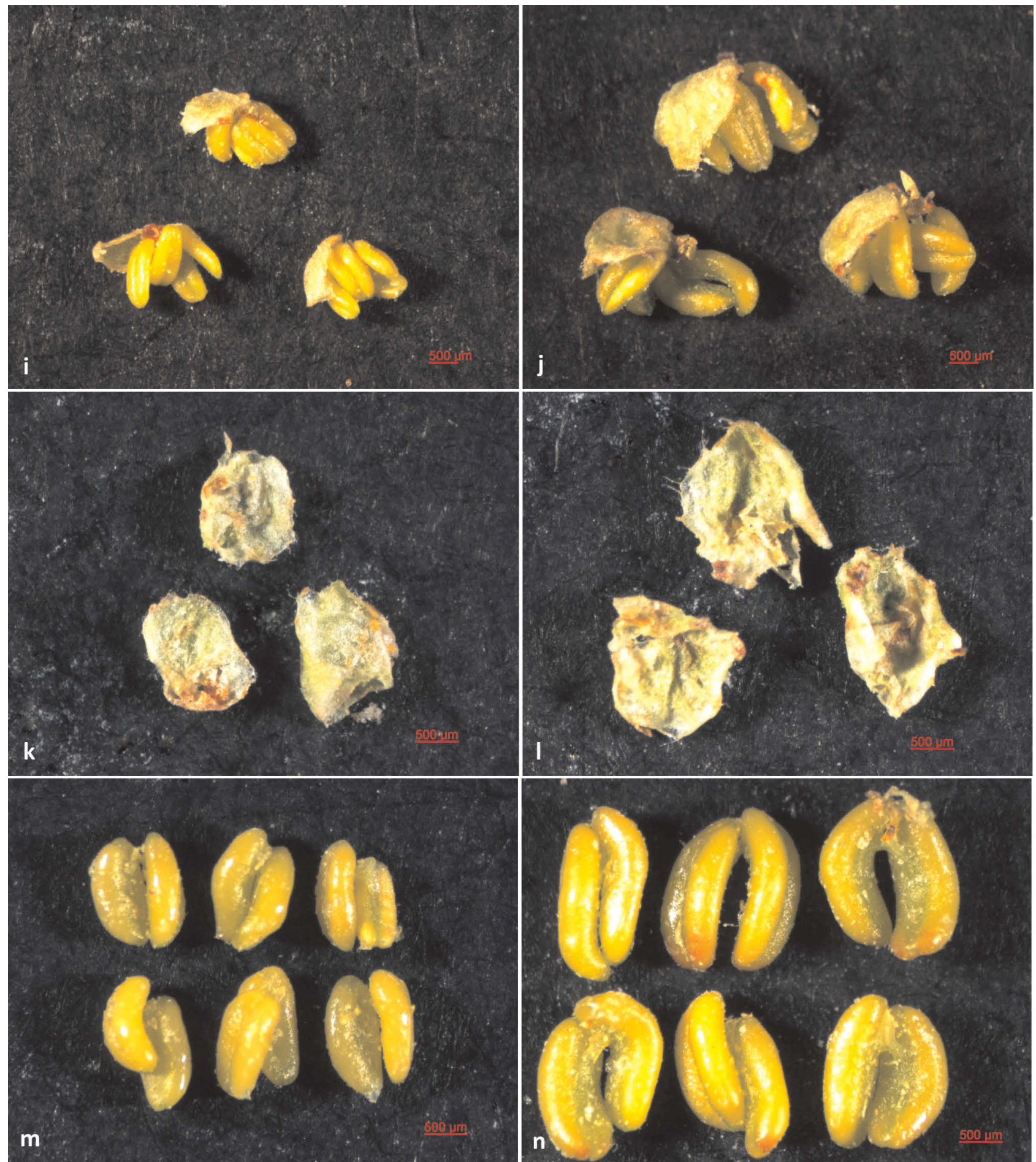

Fig. 1. Staminate flowers from diploid and autotetraploid individuals

$\mathrm{i}$ - flowers of the diploid, $\mathrm{j}$ - flowers of the autotetraploid, $\mathrm{k}$ - tepals of the diploid, 1 - tepals of the autotetraploid, $\mathrm{m}$ - anthers of the diploid, $\mathrm{n}$ - anthers of the autotetraploid. Please note that all filaments were removed

nation rate of autotetraploid Q19 was only $14.90 \%$, which was $58.89 \%$ lower than the mean rate observed for the diploids. These results indicate that pollen fertility is inferior in autotetraploids compared with the diploids.

ANOVA confirmed that there were significant variations in pollen diameters and pore depths between individual trees (Table 1). Pollen diameter and pore depth of each autotetraploid individual was significantly larger than observed for the diploids (Fig. 3 and Table 2). The largest pollen (mean diameter of 31.59 $\mu \mathrm{m})$ was from Q34, which was $35.46 \%$ larger than the mean diameter observed for the diploids, while the deepest pore depth (mean value of $3.67 \mu \mathrm{m}$ ) was measured in Q13, which was $42.25 \%$ deeper than the mean pore depth recorded for the diploid individuals. 


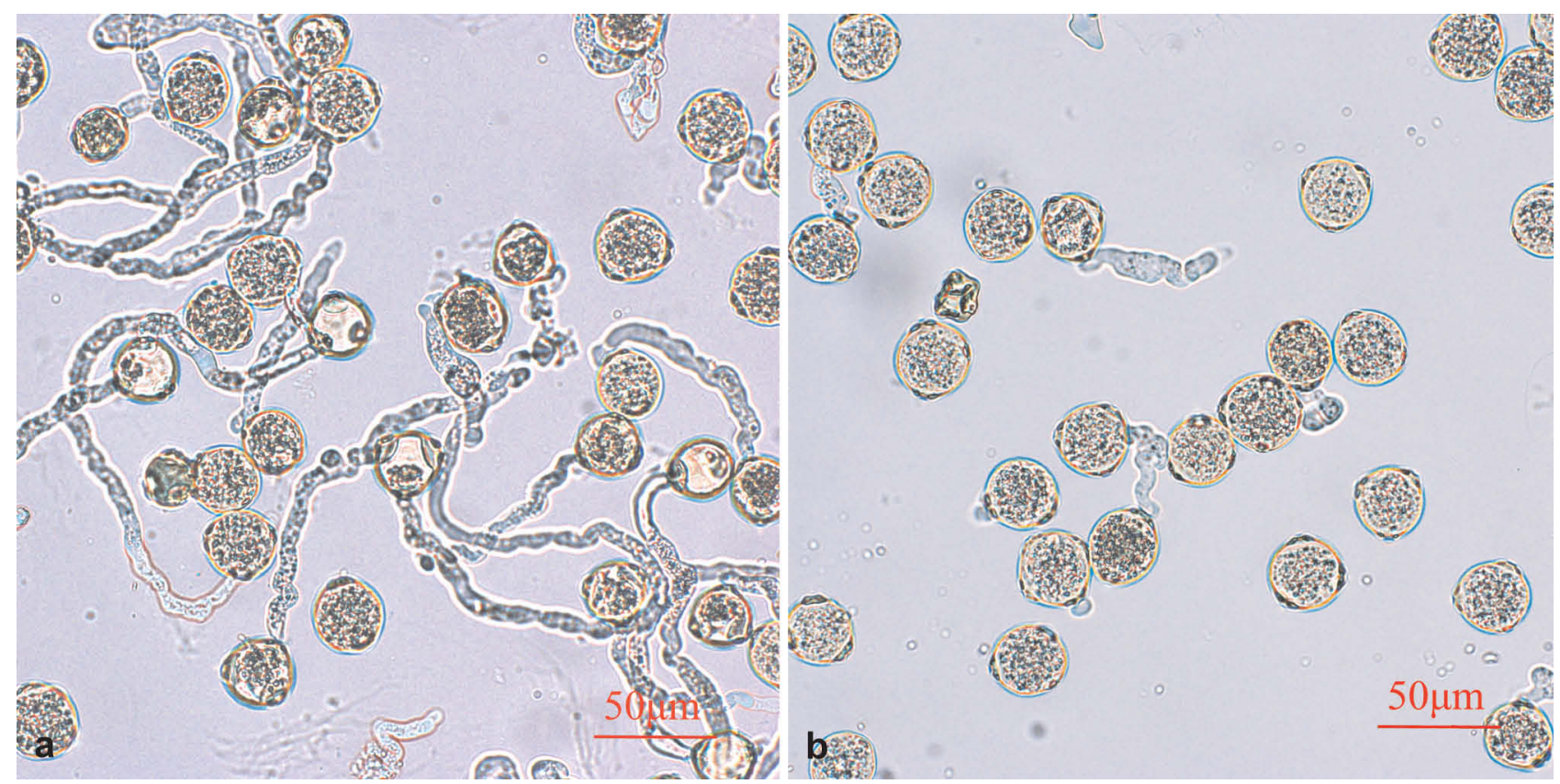

Fig. 2. Germination of pollen grains from diploid (a) and autotetraploid (b) trees

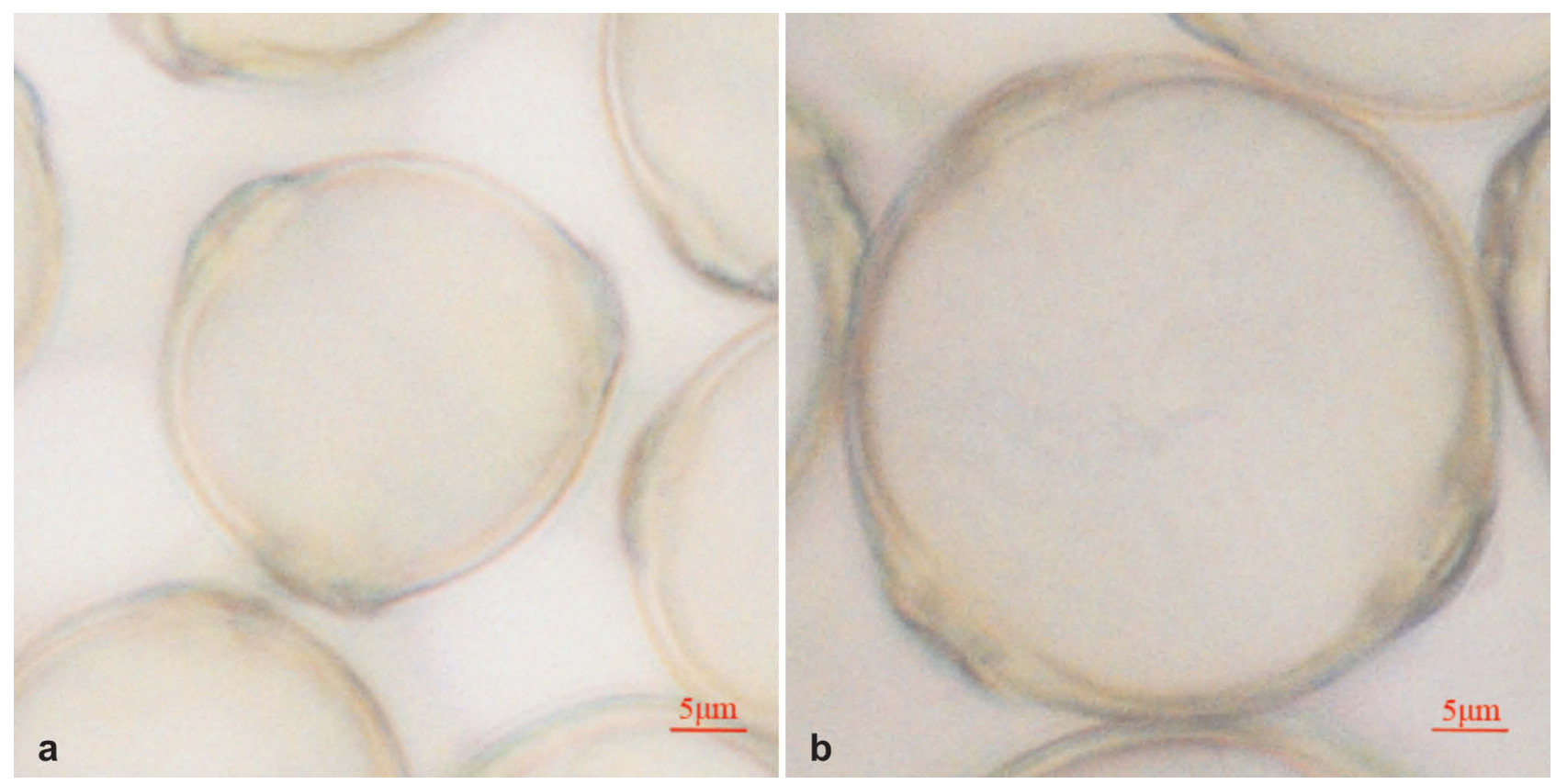

Fig. 3. Normal triporate pollen from diploid (a) and autotetraploid (b) trees

Seven classes of abnormal pollen grains were recorded: shrunken, rhombic, damaged, dwarf, uneven exine, four pores and five pores (Fig. 4). Abnormal pollen morphologies were significantly more frequent in samples from autotetraploid individuals than diploid samples (Table 1 and Table 2). Abnormal pollen in autotetraploid individuals ranged from $43.51 \%$ to $77.36 \%$, while the lowest percentage of abnormal pollen in an autotetraploid (Q19) was $982.34 \%$ greater than the mean rate calculated for diploid trees. Furthermore, there was a significant negative correlation $(r=-0.973 ; \mathrm{P}<0.01 ; \mathrm{n}=7)$ between the percentage of abnormal pollen and the ger- mination rate in autotetraploid individuals, which indicates that lower proportions of abnormal pollen are associated with greater pollen fertility.

\section{Discussion}

Variations exist in between diploid and autotetraploid plants in terms of vegetative growth, morphology, fertility and organogenesis of reproductive structures (Hao et al. 2006; Diao et al. 2010). Autotetraploids can show "gigantism" in their reproductive organs compared with diploids, but abnormal meiosis in pollen mother cells can lead to low pollen fertility in 

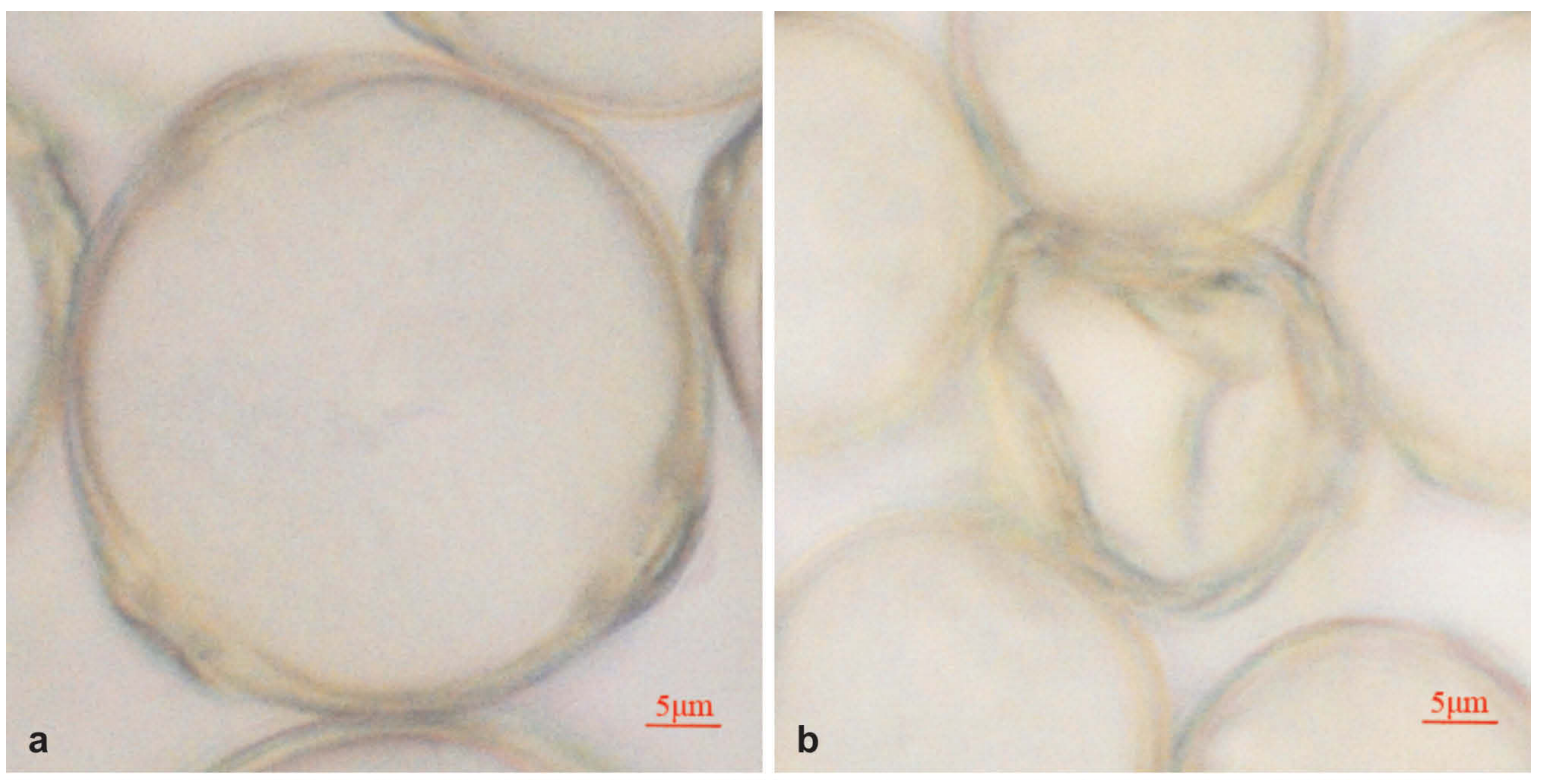

C

$5 \mu \mathrm{m}$

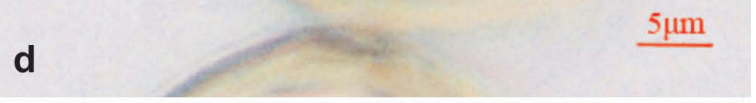

e

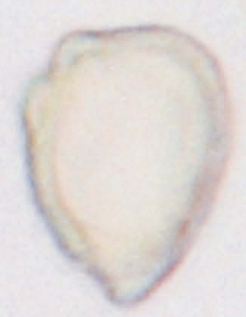

$\underline{5 \mu \mathrm{m}}$

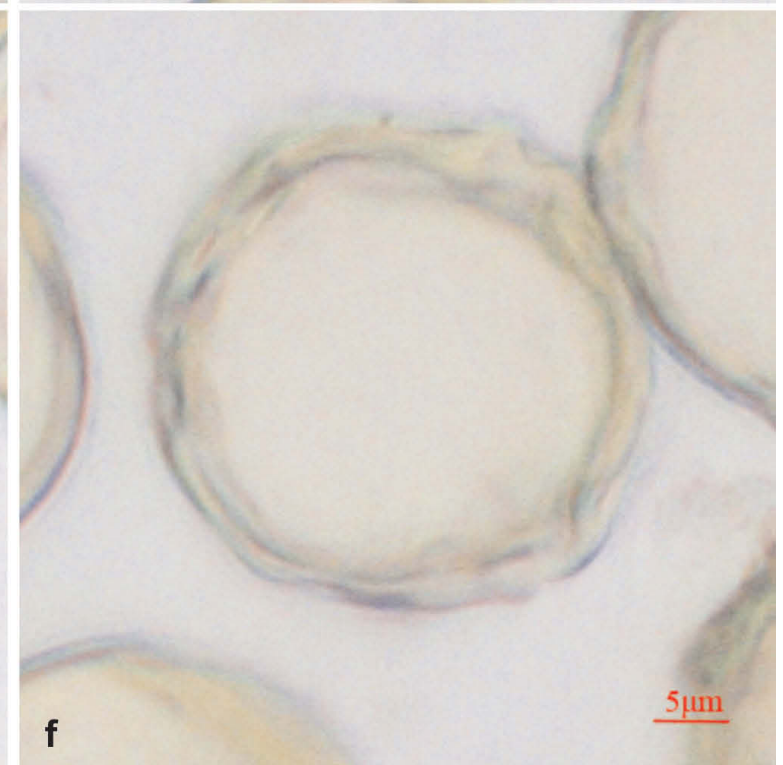

Fig. 4. Examples of abnormal pollen found in pollen samples from different trees

$\mathrm{a}$ - normal triporate type, $\mathrm{b}$ - shrunken, $\mathrm{c}$ - rhombic, $\mathrm{d}$ - damaged, $\mathrm{e}$ - dwarf, $\mathrm{f}$ - uneven exine 


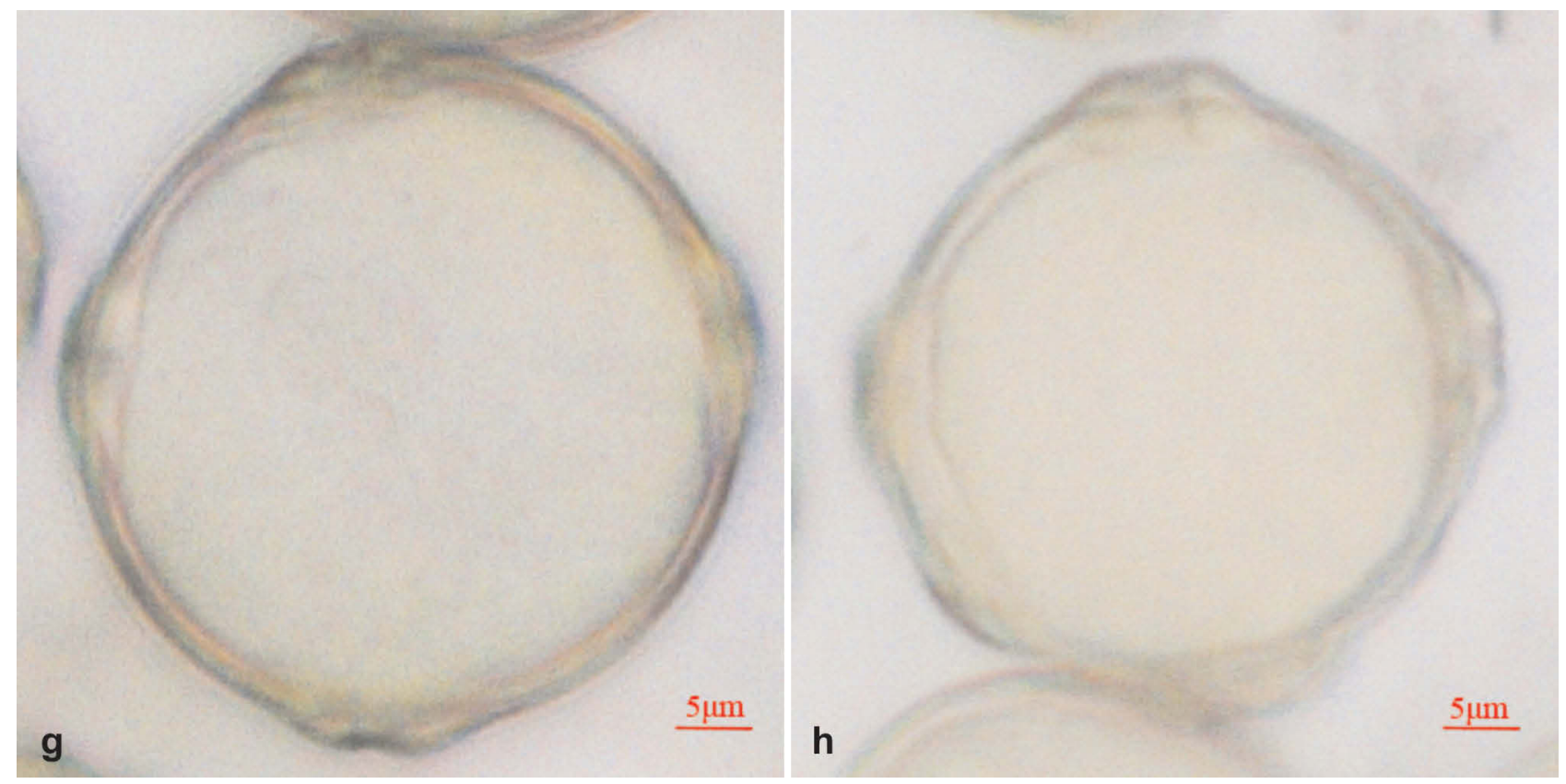

Fig. 4. Examples of abnormal pollen found in pollen samples from different trees $\mathrm{g}$ - four pores, $\mathrm{h}$ - five pores

autotetraploids. For example, the proportion of sterile pollen was up to $86.65 \%$ in autotetraploid Oryza sativa (Huang et al. 1999), while pollen fertility of autotetraploid Citrus sinensis was $36.62 \%$ lower than the diploid (Deng et al. 1995). This present study discovered that the structure of the staminate flower of autotetraploid B. platyphylla did not differ from the diploid, but that the overall size of staminate flower in the autotetraploids was larger than observed for the diploids. Moreover, the pollen from autotetraploid $B$. platyphylla individuals was significantly larger than from diploid trees. Meanwhile, there was significant variation in the size of the staminate flowers and pollen between different autotetraploid individuals. Furthermore, the germination rates and pollen tube lengths from autotetraploid individuals were lower than those from diploids, and for autotetraploids a significant negative correlation was found between the proportion of abnormal pollen and the germination rate. These phenomena may result from abnormal meiosis in pollen mother cells in the autotetraploids.

Polyploid breeding in plants has been developed using artificial methods such as colchicine and high temperature treatments (Zhu et al. 1998). Though polyploid plants sometimes exhibit certain defects such as slow growth and low fertility, others can possess excellent economic traits (Ahuja 2005; Ewald et al. 2009). In a previous study, low fertility of the male gamete but high fertility of the female gamete from autotetraploid $B$. platyphylla meant that seeds from $+2 x \times \delta^{\top} 4 x$ crosses were all sterile, while progeny saplings from $94 x \times \delta 2 x$ crosses were all triploids. These results provide an important reference for building a seed orchard of triploid birch, which is an autotetraploid tree surrounded by superior diploids. This knowledge could be used to obtain triploid seeds from abundantly available high fertility pollen, and to determine the most optimum distribution of different diploid trees to obtain superior diploid hybrids. As a result, the seed orchard of triploid birch could bring greater economic benefits via the production of superior triploid and diploid hybrid seeds.

\section{Acknowledgements}

The research was financially supported by National Forestry Department Public Benefit Research Foundation of China (201204302).

\section{References}

Ahuja M.R. 2005. Polyploidy in gymnosperms: revisited. Silvae Genetica 54: 59-69.

Blakeslee A.F., Avery A.G. 1937. Methods of inducing doubling of chromosomes in plants. Journal of Heredity 28: 393-411.

Deng X.X., Gmitter F.G., Grosser J.W. 1995. Pollen fertility of auto- and allo-tetraploids of Citrus. Acta Horticulturae Sinica 22: 16-20.

Diao W.P., Bao S.Y., Jiang B., Cui L., Qian C.T., Chen J.F. 2010. Cytological studies on meiosis and male gametophyte development in autotetraploid cucumber. Biologia Plantarum 54: 373-376.

Einspahr D.W. 1984. Production and utilization of triploid hybrid aspen. Iowa State Journal of Research 58: 401-409.

Eriksson G., Jonsson A. 1986. A review of the genetics of Betula. Scandinavian Journal of Forest Research 1: 421-434. 
Ewald D., Ulrich K., Naujoks G., Schröder M.B. 2009. Induction of tetraploid poplar and black locust plants using colchicine: chloroplast number as an early marker for selecting polyploids in vitro. Plant Cell, Tissue and Organ Culture 99: 353-357.

Hao C., Li Y., Jiang J.Z., Liu Y. 2006. The correlation between micro and mega sporogenesis's development and morphology of flower organ of tetraploid black locust. Journal of Nuclear Agricultural Sciences 20: 292-295.

Huang C.M., Huang Q.C., Li Z.Z. 1999. Polymorphism of male and female gametophytes in autotetraploidy rices. Journal of Fujian Agricultural University 28: 18-21.

Johnsson H. 1956. Auto- and allotriploid Betula families derived from colchicine treatment. Zeitschrift fur Forstgenetik und Forstpflanzenziichtüng 5: 65-70.

Johnsson H., Eklundh C. 1940. Colchicine treatment as a method in breeding hardwood species. Svensk Papperstidning 43: 373-377.

Kang X.Y. 2003. Advances in researches on polyploid breeding of forest trees. Journal of Beijing Forestry University 25: 70-74.

Karlsdóttir L., Thórsson Ć.Th., Hallsdóttir M., Sigurgeirsson A., Eysteinsson T., Anamthawat-Jónsson K. 2007. Differentiating pollen of Betula species from Iceland. Grana 46: 78-84.
Karlsdóttir L., Hallsdóttir M., Thórsson Ć.Th., Anamthawat-Jónsson K. 2008. Characteristics of pollen from natural triploid Betula hybrids. Grana 47: 52-59.

Löve Á. 1944. A new triploid Betula verrucosa. Svensk Botanisk Tidskrift 38: 381-393.

Mu M.Z., Jiang J., Li M.Y., Liu G.F. 2012. Seed vigor, photosynthesis and early growth of saplings of different triploid Betula families. Dendrobiology 68: 11-20.

Müntzing A. 1936. The chromosomes of a giant Populus tremula. Hereditas 21: 383-393.

Nilsson-Ehle H. 1936. Über eine in der nature gefundene gigasform von Populus tremula. Hereditas 21: 379-382.

Perveen A., Qaisek M. 1999. Pollen flora of Pakistan XXXI. Betulaceae. Pakistan Journal of Botany 31: 243-246.

Valanne T. 1972. Colchicine effects and colchicine-induced polyploidy in Betula. Annales Academiae Scientiarum Fennicae. Sar. A. 4: Biologica 191: $1-28$.

Zhu Z.T., Kang X.Y., Zhang Z.Y. 1997. Advances in the triploid breeding program of Populus tomentosa in China. Journal of Beijing Forestry University (English Edition) 6: 1-8.

Zhu Z.T., Kang X.Y., Zhang Z.Y. 1998. Studies on selection of natural triploids of Populus stomentosa. Scientia Silvae Sinicae 34: 22-31. 